\title{
Chiral Water Superstructures Around Anti-parallel $\beta$-sheets Observed by Chiral Vibrational Sum Frequency Generation Spectroscopy
}

Ethan A. Perets, E. Chui-Ying Yan*

AUTHOR ADDRESS: Department of Chemistry, Yale University, New Haven, Connecticut 06520

United States

Supporting Information 
(I) Methods: $\mathrm{H}_{2} \mathrm{O}-\mathrm{D}_{2} \mathrm{O}$ Kinetic Exchange

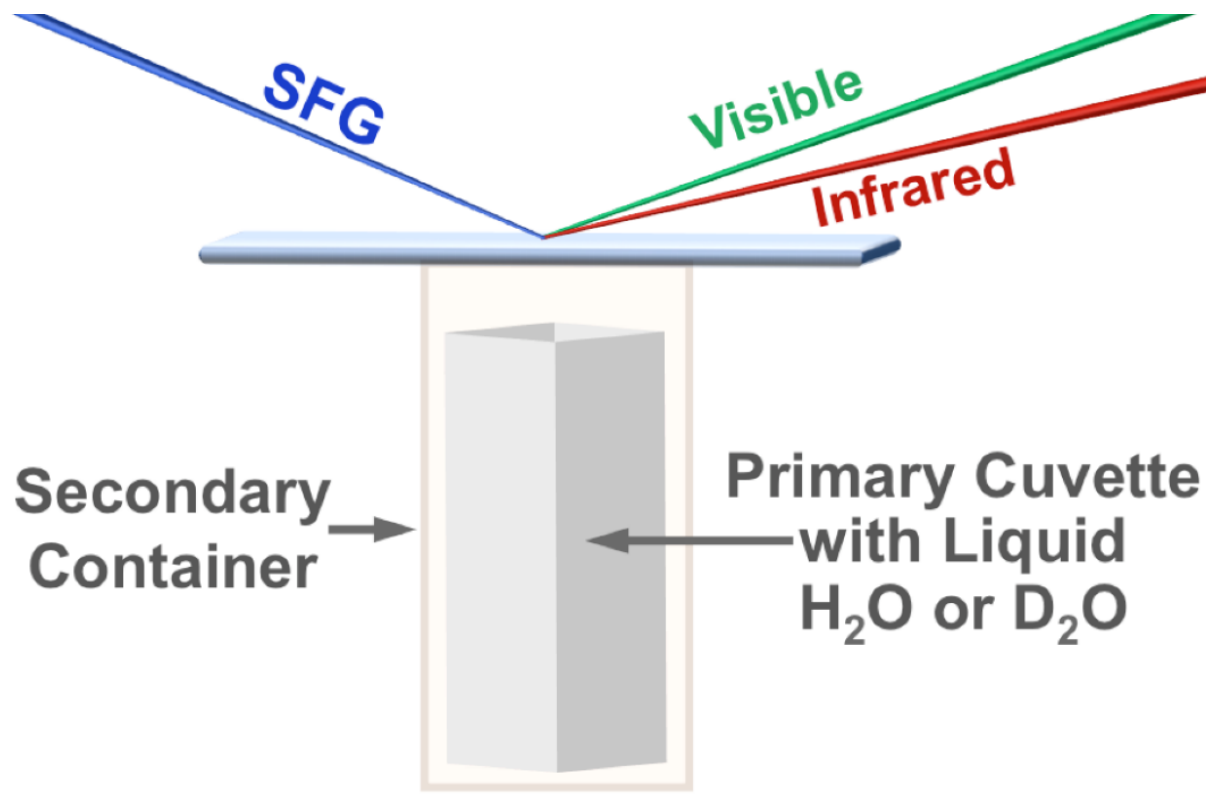

\section{(a) Side View}

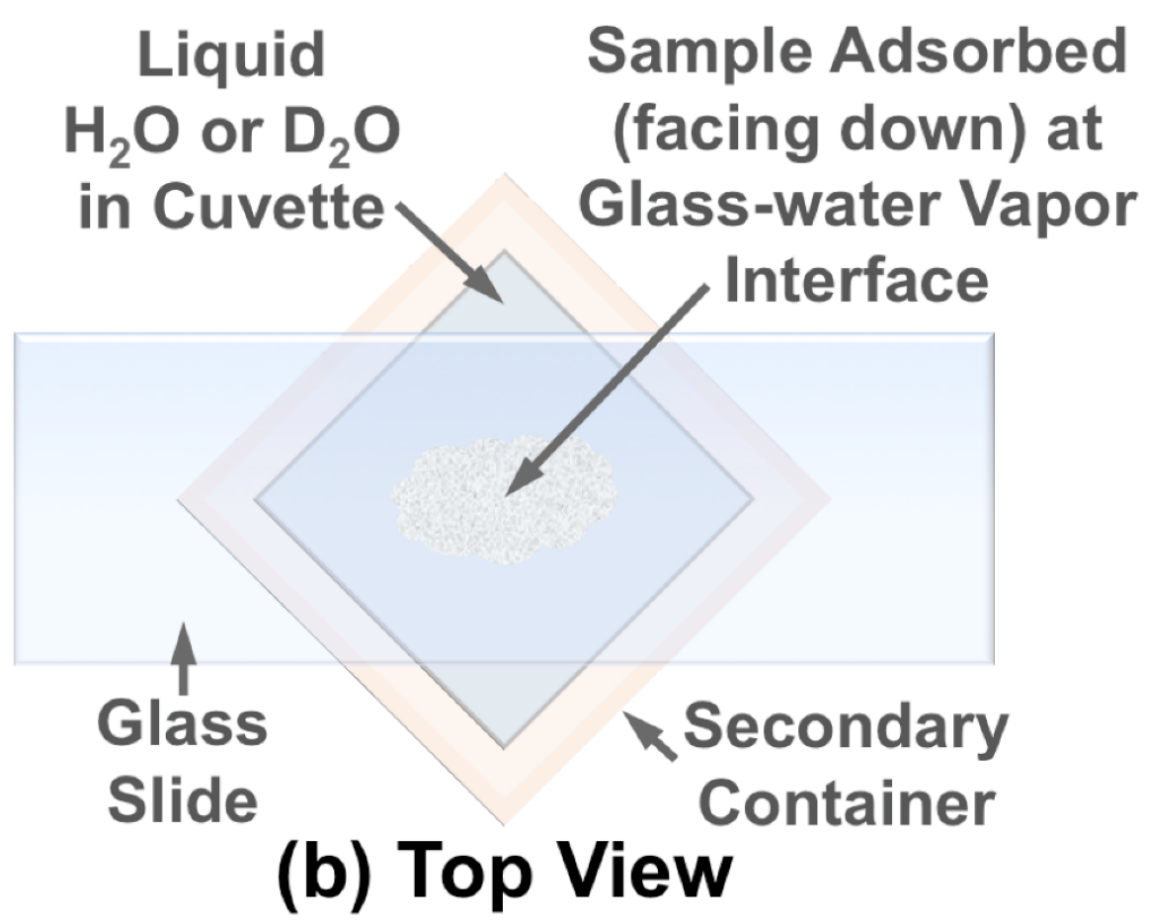

Figure S1. Schematic view (a) from the side and (b) from above of the experimental setup used for all $\mathrm{H}_{2} \mathrm{O}-\mathrm{D}_{2} \mathrm{O}$ exchange experiments. 
(II) Supplementary Data

\begin{tabular}{|c|c|c|c|}
\hline Samples & Parameters & Fittings & Assignments \\
\hline \multirow{10}{*}{$\begin{array}{c}(\mathrm{L}-) \mathrm{LK}_{7} \beta \\
\text { (Figure 1) }\end{array}$} & $\chi_{\mathrm{NR}}^{(2)}($ a.u. $)$ & $0.02 \pm 0.01$ & \\
\hline & $\omega_{1}\left(\mathrm{~cm}^{-1}\right)$ & $1565 \pm 2$ & \multirow{3}{*}{ Amide II $\left(\mathrm{LK}_{7} \beta\right)$} \\
\hline & $A_{1}$ (a.u.) & $-1.76 \pm 0.32$ & \\
\hline & $\Gamma_{1}\left(\mathrm{~cm}^{-1}\right)$ & $16.16 \pm 3.66$ & \\
\hline & $\omega_{2}\left(\mathrm{~cm}^{-1}\right)$ & $1618 \pm 1$ & \multirow{3}{*}{ Amide $\mathrm{I}, \mathrm{B}_{2}\left(\mathrm{LK}_{7} \beta\right)$} \\
\hline & $A_{2}$ (a.u.) & $10.86 \pm 0.10$ & \\
\hline & $\Gamma_{2}\left(\mathrm{~cm}^{-1}\right)$ & $11.66 \pm 0.22$ & \\
\hline & $\omega_{3}\left(\mathrm{~cm}^{-1}\right)$ & $1687 \pm 2$ & \multirow{3}{*}{ Amide $\mathrm{I}, \mathrm{B}_{1}\left(\mathrm{LK}_{7} \beta\right)$} \\
\hline & $A_{3}$ (a.u.) & $0.83 \pm 0.07$ & \\
\hline & $\Gamma_{3}\left(\mathrm{~cm}^{-1}\right)$ & $8.45 \pm 2.16$ & \\
\hline
\end{tabular}

Table S1. Fitting parameters and vibrational mode assignments for (L-) $\mathrm{LK}_{7} \beta, \mathrm{pH} 7$ in Figure 1.

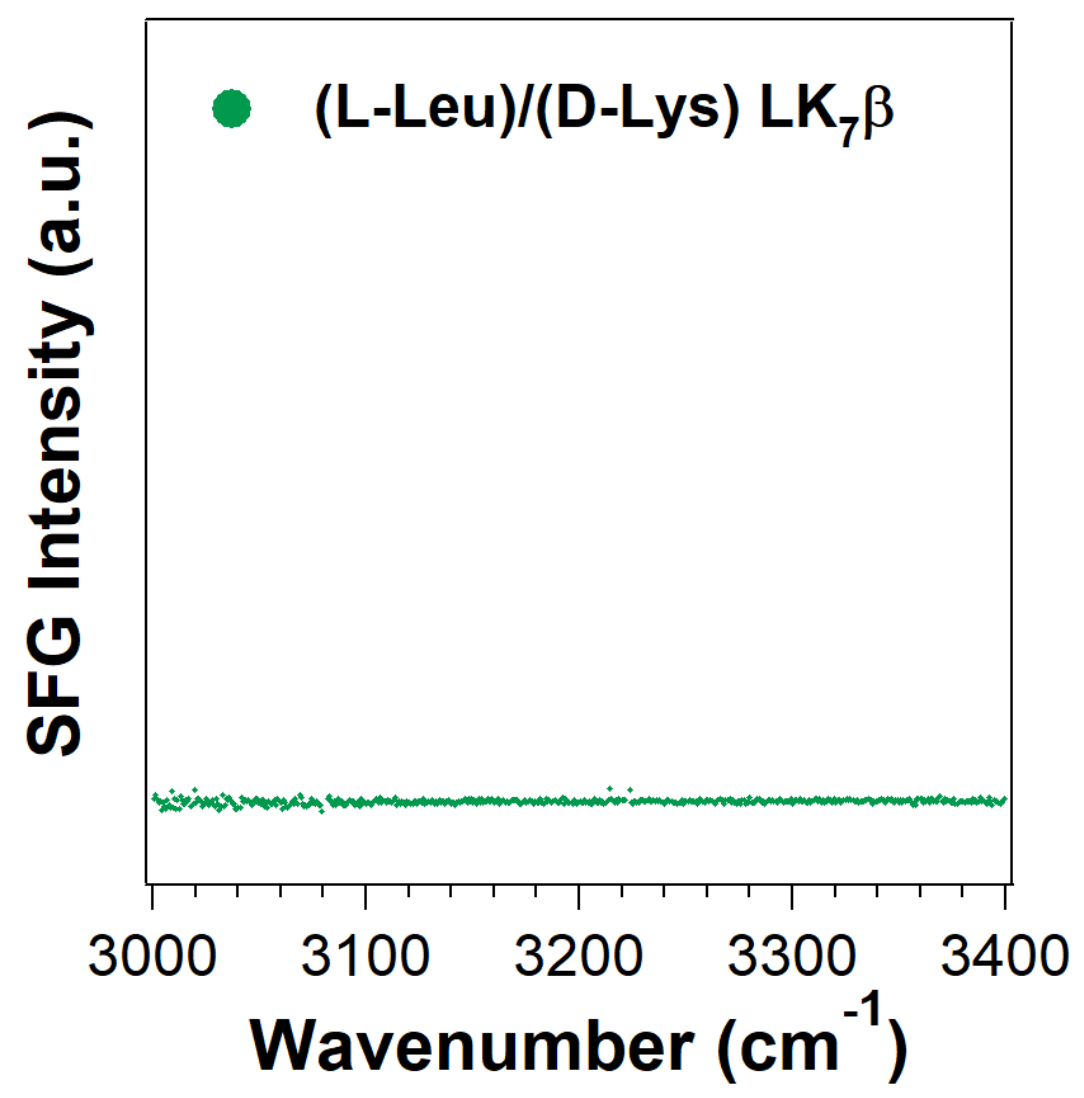

Figure S2. Chiral VSFG spectra in the $\mathrm{O}-\mathrm{H} / \mathrm{N}-\mathrm{H}$ region for (L-Leu)/(D-Lys) $\mathrm{LK}_{7} \beta$ prepared as hydrated thin-film with $\mathrm{H}_{2} \mathrm{O}$ at the air-glass interface. The chiral $\mathrm{O}-\mathrm{H}$ stretch and chiral $\mathrm{N}-\mathrm{H}$ stretch peaks are muted due to the absence of anti-parallel $\beta$-sheet secondary structure. 


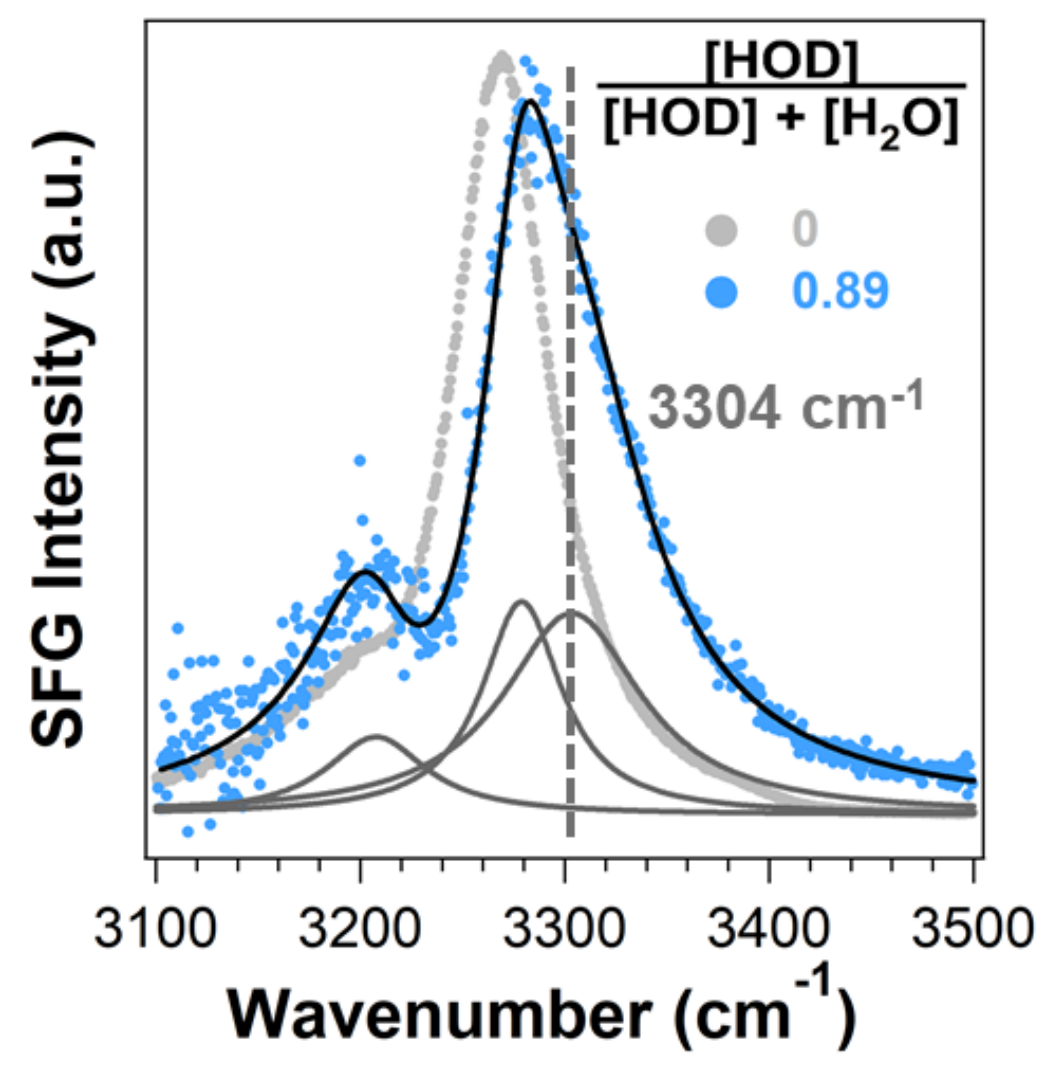

Figure S3. Component peak fittings (gray) for the chiral VSFG spectra with highest relative HOD content in Figure 4a. Overlay of spectra for volumetric ratios (gray) 1:0 and (blue) 1:4 $\mathrm{H}_{2} \mathrm{O}: \mathrm{D}_{2} \mathrm{O}$. The spectrum of $1: 4 \mathrm{H}_{2} \mathrm{O}: \mathrm{D}_{2} \mathrm{O}$ has been scaled for comparison. The fitting parameters and assignments are given below in Table S2.

\begin{tabular}{|c|c|c|c|}
\hline Samples & Parameters & Fittings & Assignments \\
\hline \multirow{10}{*}{$\begin{array}{c}\mathrm{H}_{2} \mathrm{O}: \mathrm{HOD}: \mathrm{D}_{2} \mathrm{O} \\
1: 8: 16 \\
\text { (Figure S4) }\end{array}$} & $\chi^{(2)}{ }_{N R}($ a.u. $)$ & $0.01 \pm 0.01$ & \\
\hline & $\omega_{1}\left(\mathrm{~cm}^{-1}\right)$ & $3208 \pm 1$ & \multirow{3}{*}{$\mathrm{O}-\mathrm{H}\left(\mathrm{H}_{2} \mathrm{O}\right)$} \\
\hline & $A_{1}$ (a.u.) & $1.57 \pm 0.26$ & \\
\hline & $\Gamma_{1}\left(\mathrm{~cm}^{-1}\right)$ & $29.81 \pm 2.74$ & \\
\hline & $\omega_{2}\left(\mathrm{~cm}^{-1}\right)$ & $3279 \pm 1$ & \multirow{3}{*}{$\mathrm{N}-\mathrm{H}\left(\mathrm{LK}_{7} \beta\right)$} \\
\hline & $A_{2}$ (a.u.) & $2.07 \pm 0.83$ & \\
\hline & $\Gamma_{2}\left(\mathrm{~cm}^{-1}\right)$ & $23.70 \pm 3.01$ & \\
\hline & $\omega_{3}\left(\mathrm{~cm}^{-1}\right)$ & $3304 \pm 5$ & \multirow{3}{*}{$\mathrm{O}-\mathrm{H}(\mathrm{HOD})$} \\
\hline & $A_{3}$ (a.u.) & $3.49 \pm 1.18$ & \\
\hline & $\Gamma_{3}\left(\mathrm{~cm}^{-1}\right)$ & $41.14 \pm 3.64$ & \\
\hline
\end{tabular}

Table S2. Fitting parameters and vibrational mode assignments for the isotopic dilution spectra (blue) 1:4 $\mathrm{H}_{2} \mathrm{O}: \mathrm{D}_{2} \mathrm{O}$ in Figures 4 and $\mathrm{S} 4$. 


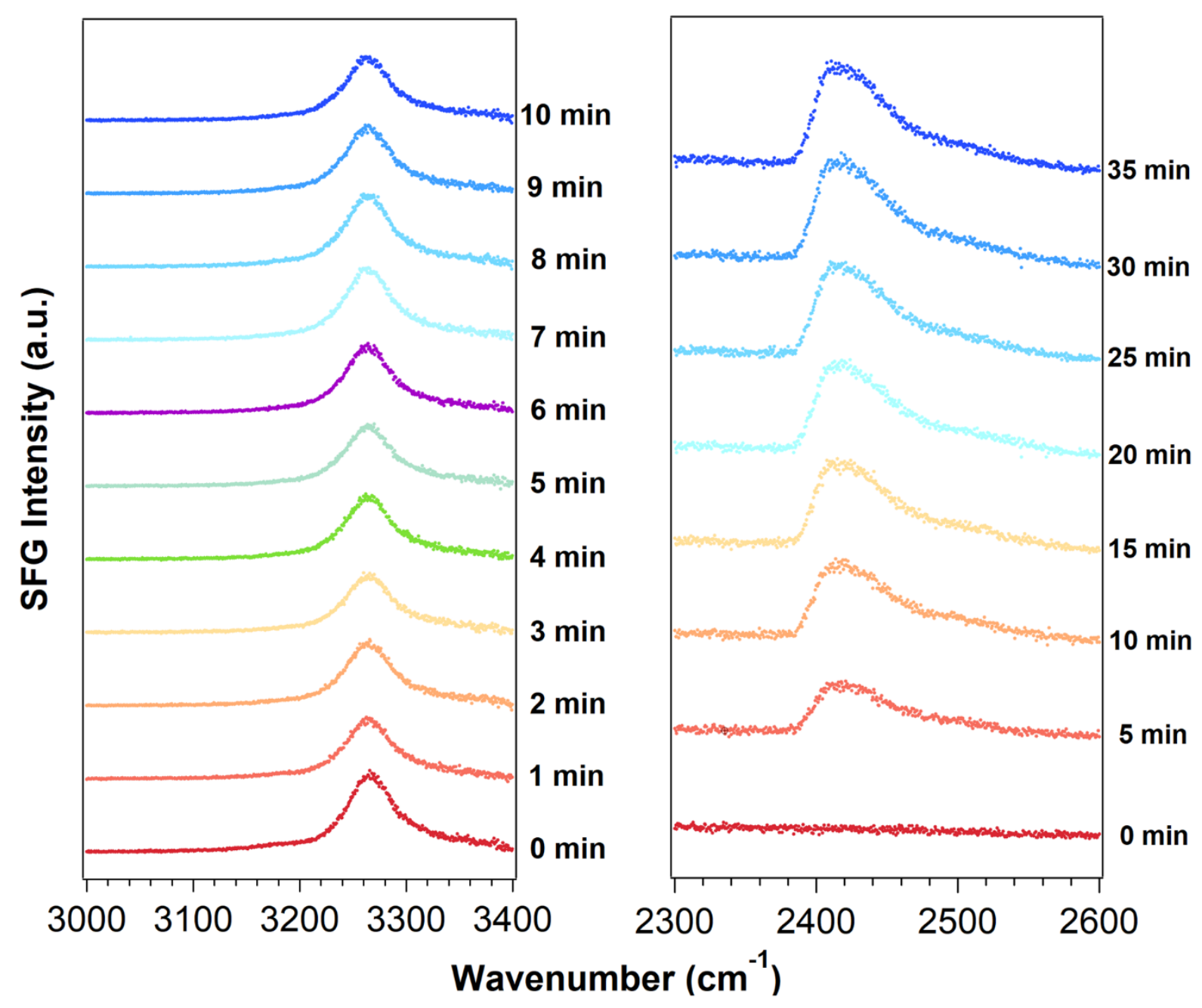

Figure S4. $\mathrm{H}_{2} \mathrm{O}$-to- $\mathrm{D}_{2} \mathrm{O}$ exchange via the vapor phase monitored by chiral VSFG over time. The spectra shown here for the (left) $\mathrm{O}-\mathrm{H} / \mathrm{N}-\mathrm{H}$ and (right) $\mathrm{O}-\mathrm{D}$ regions were fit to equation 1 . The amplitude values from the fits give the data reported in Figures $5 \mathrm{~b}$ and $5 \mathrm{~d}$ in the main text. 

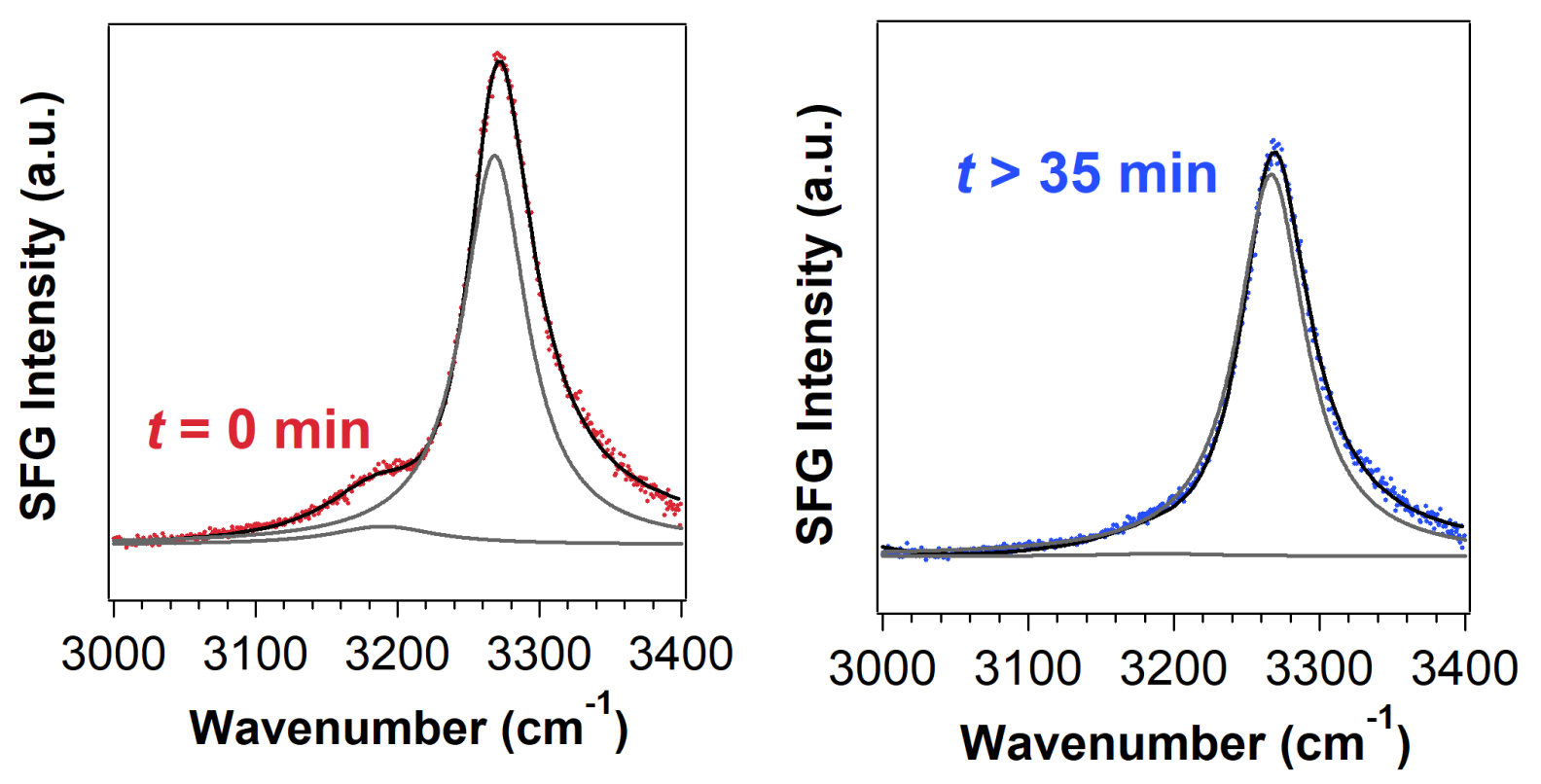

Figure S5. Component peak fittings (gray) for the chiral VSFG spectra in Figure 5a of the main text. The spectra were taken with an integration time of 10 minutes.

\begin{tabular}{|c|c|c|c|}
\hline Samples & Parameters & Fittings & Assignments \\
\hline \multirow{7}{*}{$\begin{array}{c}t=0 \mathrm{~min} \\
\text { (Figure 5a,red) }\end{array}$} & $\chi^{(2)} \mathrm{NR}$ (a.u.) & $0.01 \pm 0.01$ & - \\
\hline & $\omega_{1}\left(\mathrm{~cm}^{-1}\right)$ & $3190 \pm 1$ & \multirow{3}{*}{$\mathrm{O}-\mathrm{H}\left(\mathrm{H}_{2} \mathrm{O}\right)$} \\
\hline & $A_{1}$ (a.u.) & $1.89 \pm 0.17$ & \\
\hline & $\Gamma_{1}\left(\mathrm{~cm}^{-1}\right)$ & $44.95 \pm 2.37$ & \\
\hline & $\omega_{2}\left(\mathrm{~cm}^{-1}\right)$ & $3268 \pm 1$ & \multirow{3}{*}{$\mathrm{N}-\mathrm{H}\left(\mathrm{LK}_{7} \beta\right)$} \\
\hline & $A_{2}$ (a.u.) & $5.34 \pm 0.07$ & \\
\hline & $\Gamma_{2}\left(\mathrm{~cm}^{-1}\right)$ & $27.51 \pm 0.16$ & \\
\hline \multirow{7}{*}{$\begin{array}{c}t>35 \text { min } \\
\text { (Figure 5a,blue) }\end{array}$} & $\chi^{(2)} \mathrm{NR}$ (a.u.) & $0.01 \pm 0.01$ & \\
\hline & $\omega_{1}\left(\mathrm{~cm}^{-1}\right)$ & $3190 \pm 0 *$ & \multirow{3}{*}{$\mathrm{O}-\mathrm{H}\left(\mathrm{H}_{2} \mathrm{O}\right)$} \\
\hline & $A_{1}$ (a.u.) & $0.69 \pm 0.27$ & \\
\hline & $\Gamma_{1}\left(\mathrm{~cm}^{-1}\right)$ & $44.95 \pm 0.00^{*}$ & \\
\hline & $\omega_{2}\left(\mathrm{~cm}^{-1}\right)$ & $3267 \pm 1$ & \multirow{3}{*}{$\mathrm{N}-\mathrm{H}\left(\mathrm{LK}_{7} \beta\right)$} \\
\hline & $A_{2}$ (a.u.) & $5.37 \pm 0.16$ & \\
\hline & $\Gamma_{2}\left(\mathrm{~cm}^{-1}\right)$ & $28.27 \pm 0.74$ & \\
\hline \multirow{7}{*}{$\begin{array}{c}t>35 \mathrm{~min} \\
\text { (Figure 5c,blue) }\end{array}$} & $\chi^{(2)}$ NR (a.u.) & $0.2 \pm 0.02$ & - \\
\hline & $\omega_{1}\left(\mathrm{~cm}^{-1}\right)$ & $2410 \pm 2$ & \multirow{3}{*}{$\mathrm{O}-\mathrm{D}\left(\mathrm{D}_{2} \mathrm{O}\right)$} \\
\hline & $A_{1}$ (a.u.) & $25.31 \pm 6.36$ & \\
\hline & $\Gamma_{1}\left(\mathrm{~cm}^{-1}\right)$ & $27.08 \pm 1.29$ & \\
\hline & $\omega_{2}\left(\mathrm{~cm}^{-1}\right)$ & $2464 \pm 4$ & \multirow{3}{*}{$\mathrm{O}-\mathrm{D}\left(\mathrm{D}_{2} \mathrm{O}\right)$} \\
\hline & $A_{2}$ (a.u.) & $6.56 \pm 2.40$ & \\
\hline & $\Gamma_{2}\left(\mathrm{~cm}^{-1}\right)$ & $24.97 \pm 4.38$ & \\
\hline
\end{tabular}

*Parameters held during fitting.

Table S3. Fitting parameters and values for the chiral VSFG spectra of $\mathrm{H}_{2} \mathrm{O}-\mathrm{D}_{2} \mathrm{O}$ exchange in Figures $5 \mathrm{a}$ and $5 \mathrm{c}$ of the main text. 


\section{(III) Theoretical Background of Chiral SFG Spectroscopy}

Polarization settings and measurements of second-order susceptibility elements. SFG experiments are often set up in reflection geometry (Figure S1). The SFG intensity (ISFG) is linked to the optical electric field $\left(E_{S F G}\right)(1-3)$ :

$$
\begin{gathered}
I_{S F G}=\left|\vec{E}_{S F G}\right|^{2} \\
\vec{E}_{S F G}=E_{S F G}^{x} \widehat{x}+E_{S F G}^{y} \widehat{y}+E_{S F G}^{z} \hat{z}
\end{gathered}
$$

where $\widehat{\boldsymbol{x}}, \hat{\boldsymbol{y}}$, and $\hat{\boldsymbol{z}}$ are unit vectors. The $E_{S F G}$ field is related to the incident optical electric fields of the visible $\left(E_{v i s}\right)$ and IR $\left(E_{I R}\right)$ beams via second-order susceptibility $\chi_{i j k}^{(2)}$ :

$$
E_{S F G}^{i}=\sum_{j k} \chi_{i j k}^{(2)} E_{v i s}^{j} E_{I R}^{k}
$$

where $i, j, k=\mathrm{x}, \mathrm{y}$, or $\mathrm{z}$ are the laboratory coordinates (see Figure $\mathrm{S} 1$ for definition). Hence, $\chi_{i j k}^{(2)}$ is a 27-element tensor containing chemical and structural information. The 27-element $\chi^{(2)}$ tensor describes the electric dipole responses along three Cartesian coordinates providing enough dimension to describe molecular chirality. Thus, unlike linear chiral optical method, e.g., vibrational circular dichroism (VCD) and Raman optical activity (ROA), chiral SFG does not rely on magnetic dipole and/or electric quadruple responses that are generally weak. Hence, chiral SFG has relatively high sensitivity in detecting molecular chirality. (4-6)

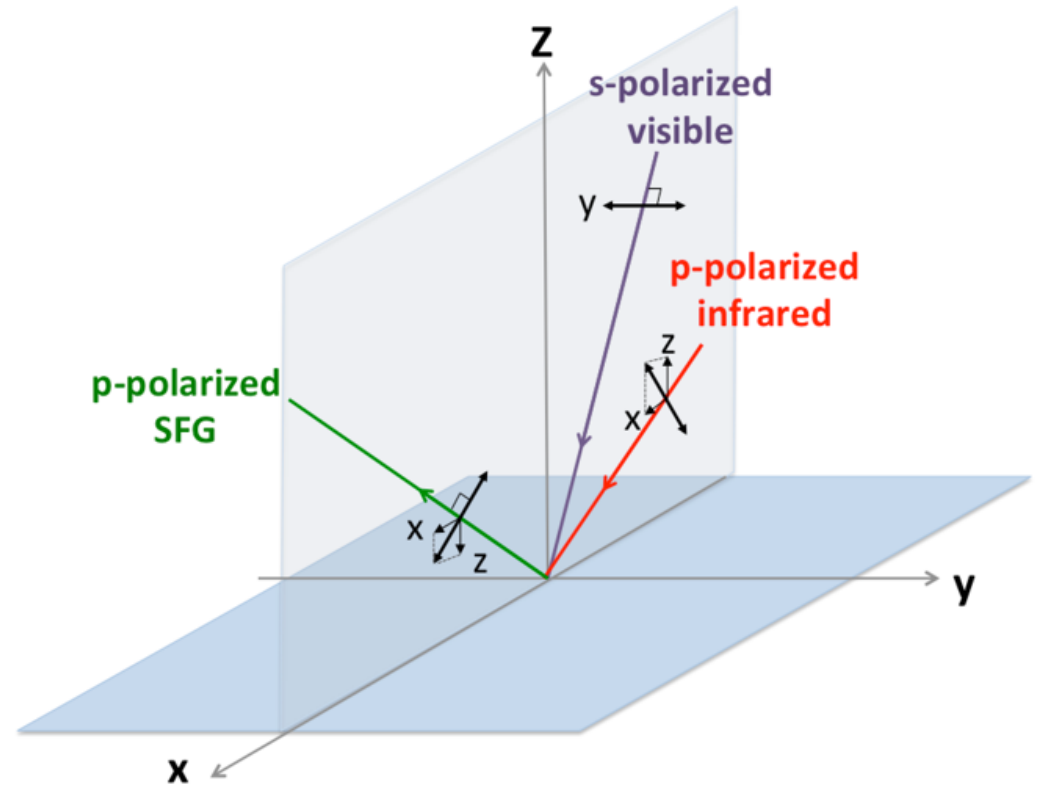

Figure S6. The $p s p$ polarization setting of SFG experiments in reflection geometry, where $p$ polarized SFG is detected and s-polarized visible and $p$-polarized infrared beams are used. Laboratory coordinates are defined with the $x-y$ plane as sample surface and the $x-z$ plane as incident plane. 
By selecting linear polarizations of the two incident beams and the SFG output signal (Figure S1), a single or a combination of the 27 tensor elements can be measured. The polarization plane can be perpendicular (s-polarized) or parallel to the incident plane ( $p$-polarized) while the $s$ - or $p$ polarized SFG signal can be measured. Under the condition that the visible incident frequency is far from resonance with the electronic transitions of the molecular system, the $p s p$ polarization ( $p$-polarized SFG, s-polarized visible, and polarized IR) measures only the $\chi_{z y x}^{(2)}$ element, where $\chi_{i \neq j \neq k}^{(2)}$ is an orthogonal second-order susceptibility element. $(5,6)$ The orthogonal element is characteristic to chiral molecular systems, which is zero for achiral molecular systems. For isotropic chiral media (e.g., chiral liquid), the orthogonal element is generally small and requires electronic resonance to be detected. $(7,8)$ However, for anisotropic chiral molecular systems, the orthogonal $\chi_{z y x}^{(2)}$ element can be comparable to other $\chi^{(2)}$ elements, giving detectable SFG signals even without electronic resonance. For such systems, an observation of chiral SFG signals from achiral molecular entities indicates these achiral molecular entities form macromolecular or supermolecular chiral structures, e.g., amide groups in protein secondary structures (9) and water molecules embedded in the minor groove of dsDNA. (10) 


\section{(IV) Polarized ATR-FTIR Experiments}

Methods. The $\mathrm{LK}_{7} \beta$ films were prepared on glass in the same manner as for SFG experiments (see Methods). Polarized ATR-FTIR data were measured with a Nicolet FTIR with diamond ATR SmartOrbit accessory (ThermoElectron Corporation), polarizer accessory (ThermoElectron Corporation), and ZnSe wire-grid polarizer (Edmund Optics). The acquisition time was 15 minutes using a resolution of $8 \mathrm{~cm}^{-1}$. The experiment was reproduced with three independent samples.

Analysis. The polarization dependent absorbance (dichroic ratio) of the Amide I mode ( $\mathrm{vC}=\mathrm{O}$ of the peptide backbone) at $1625 \mathrm{~cm}^{-1}$ and Amide II mode ( $\mathrm{vC}-\mathrm{N}$ of the peptide backbone) at 1538 $\mathrm{cm}^{-1}$ were compared. Different dichroic ratios for Amide I and Amide II modes should indicate a non-random (anisotropic) orientation of the $\beta$-sheets. (11)

Measurement of the Amide II dichroic ratio reveals the bulk average orientation of the $\beta$-strand axis of $\mathrm{LK}_{7} \beta$. According to the analysis of Marsh, (12) the Amide II dichroic ratio depends on the average tilt $(\gamma)$ of the $\beta$-strand axis relative to surface normal according to:

$$
R_{\text {AmideII }}^{A T R}=A+\frac{2 B \cos ^{2}(\gamma)}{1-2 \cos ^{2}(\gamma)}
$$

where, considering the $\mathrm{x}, \mathrm{y}, \mathrm{z}$ components of the electric field $E$ of the incident IR beam, $A$ is $\left(E_{x}{ }^{2} / E_{y}^{2}\right)$ and $B$ is $\left(E_{z}{ }^{2} / E_{y}^{2}\right)$. Calculation of $A$ and $B$ depend on the incident angle of the IR beam $\left(45^{\circ}\right)$ and the refractive indices of the ATR-FTIR crystal $\left(n_{\text {diamond }}=2.42\right)$ and protein $\left(n_{\text {protein }}=1.4\right)$.

Results. The dichroic ratio of the Amide I mode ( $\mathrm{vC}=\mathrm{O}$ of the peptide backbone) at $1625 \mathrm{~cm}^{-1}$ is $\boldsymbol{R}_{\text {AmideI }}^{\text {ATR }}=\mathrm{A}_{0^{\circ}} / \mathrm{A}_{90^{\circ}}=1.06 \pm 0.04$. The dichroic ratio of the Amide II mode ( $\mathrm{vC}-\mathrm{N}$ of the peptide backbone) at $1538 \mathrm{~cm}^{-1}$ is $\boldsymbol{R}_{\text {AmideII }}^{\text {ATR }}=\mathrm{A}_{0^{\circ}} / \mathrm{A}_{90^{\circ}}=1.27 \pm 0.02$.

According to the result, the $\beta$-strands demonstrate an average tilt away from the surface normal by $\gamma=63^{\circ} \pm 1^{\circ}$. This result agrees with MD simulations of $\mathrm{LK}_{7} \beta$ at the air-water interface carried out by Weidner and co-workers, who reported an average orientation of $\mathrm{LK}_{7} \beta$ of $\gamma=62^{\circ} \pm 39^{\circ}$. (13)

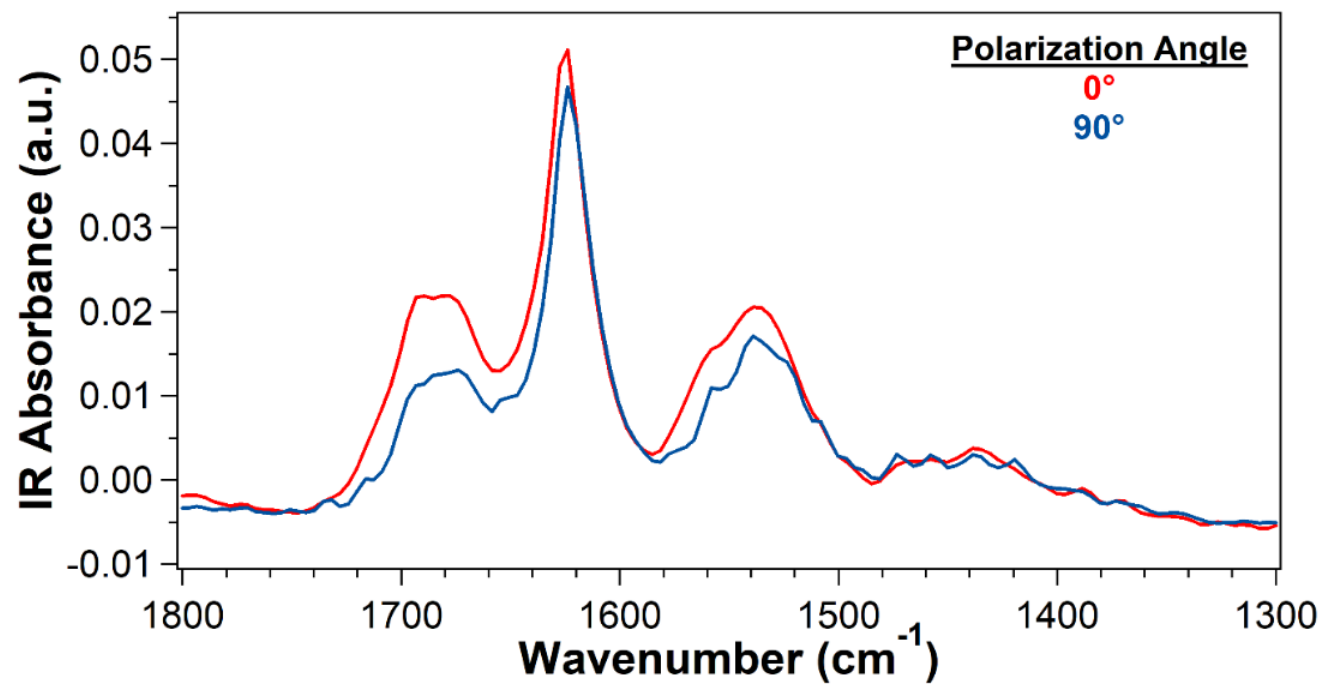

Figure S7. ATR-FTIR polarization dependence of $\mathrm{LK}_{7} \beta$ hydrated thin-films adsorbed on glass. 


\section{REFERENCES}

1. Shen, Y. Surface properties probed by second-harmonic and sum-frequency generation. Nature 1989, 337, 519.

2. Eisenthal, K. B. Equilibrium and dynamic processes at interfaces by second harmonic and sum frequency generation. Annu. Rev. Phys. Chem. 1992, 43, 627-661.

3. Messmer, M. C.; Conboy, J. C.; Richmond, G. L. Observation of molecular ordering at the liquid-liquid interface by resonant sum frequency generation. J. Am. Chem. Soc. 1995, 117, 8039-8040.

4. Haupert, L. M.; Simpson, G. J. Chirality in nonlinear optics. Annu. Rev. Phys. Chem. 2009, 60, 345-365.

5. Simpson, G. J. Nonlinear Optical Polarization Analysis in Chemistry and Biology. Cambridge University Press: Cambridge; 2017.

6. Yan, E. C.; Fu, L.; Wang, Z.; Liu, W. Biological macromolecules at interfaces probed by chiral vibrational sum frequency generation spectroscopy. Chem. Rev. 2014, 114, 84718498.

7. Belkin, M. A.; Kulakov, T. A.; Ernst, K. H.; Yan, L.; Shen, Y. R. Sum-Frequency Vibrational Spectroscopy on Chiral Liquids: A Novel Technique to Probe Molecular Chirality. Phys. Rev. Lett. 2000, 85, 4474-4477.

8. Lee, T.; Rhee, H.; Cho, M. Femtosecond Vibrational Sum-Frequency Generation Spectroscopy of Chiral Molecules in Isotropic Liquid. The Journal of Physical Chemistry Letters 2018, 9, 6723-6730.

9. Yan, E. C.; Wang, Z.; Fu, L. Proteins at interfaces probed by chiral vibrational sum frequency generation spectroscopy. The Journal of Physical Chemistry B 2015, 119, 2769-2785.

10. McDermott, M. L.; Vanselous, H.; Corcelli, S. A.; Petersen, P. B. DNA's chiral spine of hydration. ACS central science 2017, 3, 708-714.

11. Aggeli, A.; Boden, N.; Cheng, Y.-L.; Findlay, J. B. C.; Knowles, P. F.; Kovatchev, P.; Turnbull, P. J. H.; Horváth, L.; Marsh, D. Peptides Modeled on the Transmembrane Region of the Slow Voltage-Gated IsK Potassium Channel: Structural Characterization of Peptide Assemblies in the $\beta$-Strand Conformation. Biochemistry 1996, 35, 16213-16221.

12. Marsh, D. Dichroic ratios in polarized Fourier transform infrared for nonaxial symmetry of beta-sheet structures. Biophys. J. 1997, 72, 2710-2718.

13. Donovan, M. A.; Lutz, H.; Yimer, Y. Y.; Pfaendtner, J.; Bonn, M.; Weidner, T. LK peptide side chain dynamics at interfaces are independent of secondary structure. Phys. Chem. Chem. Phys. 2017, 19, 28507-28511. 